\title{
Variation Effects of Mobile Phone Frequencies and Exposure Durations on Selected Oxidative Stress Biomarkers of Male Wistar Albino Rats
}

Iheme $\mathrm{Cl}^{1 *}$, Omeh $\mathrm{YN}^{2}$ and Nwuke $\mathrm{CP}^{2}$

${ }^{1}$ Department of Biochemistry, Federal University of Technology, Nigeria

${ }^{2}$ Department of Biochemistry, Micheal Okpara University of Agriculture, Nigeria

\begin{abstract}
The effects of different frequencies and exposure duration on selected oxidative stress biomarkers of male albino wistar rats were studied. Sixty (60) rats were used for the study. The rats were divided into two major groups of thirty (30) rats each, and each major group were further divided into sub-groups, I-VI, of five (5) rats each according to their weights. The rats in major groups, A and B, were exposed for ninety (90) and one hundred and eighty (180) days respectively. The rats in sub-group I, II, and III were exposed to $900 \mathrm{MHz}$ field from mobile phones for $5 \mathrm{~h} /$ day, 10 $\mathrm{h} /$ day, $15 \mathrm{~h}$ /day respectively, while the rats in subgroup IV were exposed to $2.4 \mathrm{GHz}$ field for $24 \mathrm{~h} /$ day. Rats in subgroups $\mathrm{V}$ and $\mathrm{VI}$ were the normal and negative controls respectively. At the end of 90 and 180 days, the rats were anaesthetized; blood samples were collected for assessment of oxidative stress biomarkers. The activities of SOD, CAT and the concentration of MDA from subgroup III were $12.69 \pm 0.60,14.74 \pm 0.07$, and $2.03 \pm 0.10$ respectively. The activities of SOD, CAT and the concentration of MDA at these varying exposure time for 90 days duration were significantly $(p<0.05)$ higher than those of positive and negative controls which were $8.64 \pm 0.35,9.60 \pm 0.47,1.03 \pm$ 0.02 and $9.04 \pm 0.02,10.43 \pm 0.51,1.20 \pm 0.20$ respectively. At the exposure duration of 180 days, the activities of the SOD, CAT and the concentration of MDA were assessed. The activities of SOD, CAT and the concentration of MDA from subgroup III were $13.47 \pm 0.51,14.84 \pm 0.07$, and $2.11 \pm 0.10$ respectively. The activities of SOD, CAT and the concentration of MDA at these varying exposure time for 180 days were significantly $(p<0.05)$ higher than those of positive and negative controls which were $8.91 \pm 0.10,9.94 \pm 0.13,1.18 \pm 0.19$; and $9.09 \pm 0.03,10.45 \pm 0.49,1.38$ \pm 0.20 respectively. At the different frequency of $2.4 \mathrm{GHz}$, the activities of the enzyme and the concentration of MDA were also assayed. At the exposure of 90 days duration, the activities of SOD, CAT and the concentration of MDA were $14.49 \pm 0.29,15.77 \pm 0.10$, and $2.67 \pm 0.04$ respectively. At the exposure of 180 days duration, the activities of SOD, CAT and MDA were $14.96 \pm 0.10,15.86 \pm 0.11$, and $3.00 \pm 0.08$ respectively. In general, the activities of SOD, CAT and MDA at the frequency of $2.4 \mathrm{GHz}$ for the exposure duration of 90 and 180 days were significantly $(p<0.05)$ higher than those positive and negative controls. From our findings, it can be concluded that different frequencies $(900 \mathrm{MHz}$ and $2.4 \mathrm{GHz}$ ) and exposure durations (90 and 180 days), can induce oxidative stress in living system.
\end{abstract}

Keywords: Frequency; Exposure duration; Mobile phone; Oxidative stress markers

\section{Background of Study}

Mobile phones send and receive electromagnetic signals at the frequency range of $900 \mathrm{MHz}$ to $950 \mathrm{MHz}$ [1]. This is unlike wifi which sends signals at an incredible frequency of $2.4 \mathrm{GHz}$. Radiation at this frequency is capable of penetrating through every biological membrane with its attendant effects on organic molecules [2,3]. The radiation from mobile phone, though, non-ionizing radiation (NIR), yet myriad of experimental data have revealed its potency to affecting living cells, which include in vitro and in vivo changes in the biochemical and molecular mechanisms of cells [4]. Different factors have been linked to influencing the interaction of electromagnetic radiation with biological systems and these factors include EMR power density and frequency, proximity to the radiation source, duration of exposure, polarization and the nature of the biological sample [5].

Electromagnetic particles travel through the space at an incredible speed of $3 \times 10^{8} \mathrm{~m} / \mathrm{sec}(186,000$ miles/second) penetrating solid surfaces of all kinds and natures. Electromagnetic energy can be characterized by wavelength and frequency. Whereas, the wavelength $(\lambda)$ is the distance covered by one complete electromagnetic wave cycle, the frequency ( $\mathrm{f}$ ) is the number of electromagnetic waves passing a given point in one second and both share inverse relationship, represented as: $f=\frac{c}{\lambda}$ where $\mathrm{C}=$ speed [6]. This work is aimed at investigating the variation effects of frequency and exposure duration on oxidative stress biomarkers of male wistar rats. The biomarkers assayed in the study were the malondialdehyde concentration, activities of catalase and superoxide dismutase.

\section{Catalase}

Catalase is a heam-containing enzyme which consists of four protein subunits, each of which contains a haem group and a molecule of NADPH. It is mostly found in the peroxisome of cells where hydrogen peroxide and other related compounds are produced. The decomposition of a pro-radical, hydrogen peroxide $\left(\mathrm{H}_{2} \mathrm{O}_{2}\right)$, to water and oxygen is catalyzed by the catalase [7]. The reaction involves two stages viz:

$$
\begin{aligned}
& \text { Catalase-Fe (III) }+\mathrm{H}_{2} \mathrm{O}_{2} \rightarrow \text { Compound A } \\
& \text { Compound } \mathrm{A}+\mathrm{H}_{2} \mathrm{O}_{2} \rightarrow \text { Catalase-Fe (III) }+2 \mathrm{H}_{2} \mathrm{O}+\mathrm{O}_{2}
\end{aligned}
$$

*Corresponding author: Iheme $\mathrm{Cl}$, Department of Biochemistry, Federal University of Technology, Nigeria, Tel: (+234) 7031014133; E-mail: callistus.iheme@futo.edu.ng

Received: August 22, 2018; Accepted: August 29, 2018; Published September 05, 2018

Citation: Iheme Cl, Omeh YN, Nwuke CP (2018) Variation Effects of Mobile Phone Frequencies and Exposure Durations on Selected Oxidative Stress Biomarkers of Male Wistar Albino Rats. Biochem Anal Biochem 7: 360. doi: 10.4172/21611009.1000360

Copyright: ( $) 2018$ Iheme $\mathrm{Cl}$, et al. This is an open-access article distributed under the terms of the Creative Commons Attribution License, which permits unrestricted use, distribution, and reproduction in any medium, provided the original author and source are credited. 


\section{Superoxide dismutase (SOD)}

Superoxide Dismutase (SOD) is the first line of defense against superoxide radicals and oxidative stress is Superoxide dismutase (SOD) [8]. It catalyzes the dismutation of superoxide $\left(\mathrm{O}_{2}^{-}\right)$to hydrogen peroxide $\left(\mathrm{H}_{2} \mathrm{O}_{2}\right)$.

$$
\mathrm{O}_{2}^{-}+\mathrm{O}_{2}^{-}+2 \mathrm{H}^{+} \rightarrow \mathrm{H}_{2} \mathrm{O}_{2}+\mathrm{O}_{2}
$$

The hydrogen peroxide formed is metabolized by catalase or glutathione peroxidase to $\mathrm{H}_{2} \mathrm{O}$ and $\mathrm{O}_{2}$. The three forms of SOD in mammals which are specific in their subcellular locations and tissues distributions are Copper Zinc Superoxide Dismutase (CuZn SOD) located in the cytoplasm and organelles of most mammalian cells; Manganese Superoxide Dismutase (Mn SOD) found in the mitochondria of almost all cells and Extracellular Superoxide Dismutase (EC SOD) synthesized in cell types as fibroblasts and endothelial cells and expressed on cell surface bound to heparansulphates [9].

\section{Malondialdehyde}

Malondialdehyde is the end product of lipid peroxidation and serves as the bio-indicator of lipid peroxidation [10]. Malondialdehyde is a reactive aldehyde and one of the most reactive electrophile species that causes cellular stress. It covalently bonds with proteins to form protein adducts, referred to as advanced lipoxidation end products (ALE). The level of oxidative stress damage in an organism is measured by the concentration of this aldehyde [11].

\section{Materials and Methods}

Tecno Y2 wifi-enabled mobile phones (China) of frequency 900 $\mathrm{MHz}$, wifi frequency of $2.4 \mathrm{GHz}$, and Acoustimeter RF meter model AM-10 radio frequency meter (EMFields, UK).

\section{Experimental design}

Sixty (60) rats at the age of 32 days, weight range of 42.6-78.8 g, were used for the study. After two weeks of acclimatization, the rats were grouped into two major groups (A and B) of thirty (30) rats each. Group A was exposed for ninety (90) days, while group B was exposed for one hundred and eighty (180) days. Rats in each group were further grouped into sub-groups of five (5) rats each, according to their weights and exposure periods per day. Radiation was generated in sub-group I to III by flashing the phones from other phones for the exposure periods ranging from 5 to $15 \mathrm{~h}$ /day. The mobile phones were kept in close proximity to the rats in the cages by suspending the phones at the center of the cages using binding wires. The animals in sub-group I, II and III were exposed to the $900 \mathrm{MHz}$ field for 5, 10, and $15 \mathrm{~h}$ /day respectively. Sub-group IV was exposed to $2.4 \mathrm{GHz}$ field from the mobile phone Wifi for $24 \mathrm{~h} /$ day. Sub-group V was the normal control devoid of any source of the radiation (phone). Sub-group VI was the negative control, with mobile phone powered on $24 \mathrm{~h} /$ day, but no call was made to it.

The rats were weighed every week and calls durations were recorded throughout the period of the experiment. Also, it was ensured that the cages were kept $5 \mathrm{~m}$ apart from each other so as not to expose the control to electromagnetic radiation (EMR) and so that the calls would not interfere with each other (Table 1). This is illustrated on the table below.

\section{Collection of blood samples}

After ninety (90), and one hundred and eighty (180) days of exposure, the rats were anaesthetized with dichloromethane and

\begin{tabular}{|c|c|c|}
\hline Sub-groups & Group A (90days) & Group B (180 days) \\
\hline Group I ( 5 h/day) & 5 rats & 5 rats \\
\hline Groupll (10 h/day) & 5 rats & 5 rats \\
\hline Group III (15 h/day) & 5 rats & 5 rats \\
\hline Group IV (wifi 24 h/day) & 5 rats & 5 rats \\
\hline Group V (normal control) & 5 rats & 5 rats \\
\hline GroupVI (Negative control) & 5 rats & 5 rats \\
\hline & $\mathrm{N}=30$ & $\mathrm{~N}=30$ \\
\hline
\end{tabular}

Table 1: Experimental design.

sacrificed. The blood samples were collected aseptically using needles and syringes under the right conditions and temperature using ocular and cardiac puncture methods. The blood samples were put into EDTA bottles to prevent the blood from coagulating and were labeled properly for analysis according to the groups.

\section{Oxidative stress parameters}

Determination of lipid peroxidation (malondialdehyde): Lipid peroxidation was determined spectrophotometrically by measuring the level of the lipid peroxidation product, malondialdehyde (MDA) as described by Wallin et al. [12].

Procedure: The serum of $0.1 \mathrm{ml}$ was mixed with $0.9 \mathrm{ml}$ of water in a beaker. After that, $0.5 \mathrm{ml}$ of $25 \%$ TCA (trichloroacetic acid) and $0.5 \mathrm{ml}$ of $1 \%$ TBA (thiobarbituric acid) in $0.3 \% \mathrm{NaOH}$ were also added to the mixture. The mixture was boiled for $40 \mathrm{~min}$ at $95^{\circ} \mathrm{C}$ in a water-bath and then cooled in cold water. Then, $0.1 \mathrm{ml}$ of $20 \%$ sodium dodecylsulphate (SDS) was added to the cooled solution and mixed properly. The absorbance's were taken at $532 \mathrm{~nm}$ and $600 \mathrm{~nm}$ against the blank.

Assay for catalase activity: The activity of catalase was assayed according to the method of Abei [13].

Procedure: Initially $2.5 \mathrm{ml}$ of phosphate buffer, $2 \mathrm{ml} \mathrm{H}_{2} \mathrm{O}_{2}$ and 0.5 $\mathrm{ml}$ of sample were pipetted into a test tube. $1 \mathrm{ml}$ portion of the reaction mixture was taken and added to $2 \mathrm{ml}$ of dichromate-acetic acid reagent. The absorbance of catalase activity at $240 \mathrm{~nm}$ was determined at a min interval for 4 minutes.

Assay of superoxide dismutase (SOD) activity: The activity of superoxide dismutase was assayed using the method of Xin et al. [14] SOD reduces superoxide to hydrogen peroxide.

Procedure: Into a test tube, $0.9 \mathrm{ml}$ of distilled water and $0.1 \mathrm{ml}$ of sample were pipetted and mixed. $0.1 \mathrm{ml}$ of this mixture was taken and mixed with $0.9 \mathrm{ml}$ of carbonate buffer and $75 \mu \mathrm{l}$ of xanthine oxidase added. The absorbance was determined at $500 \mathrm{~nm}$ for $3 \mathrm{mins}$ at 20 $\mathrm{s}$ intervals. The rate of change of absorbance was used to determine superoxide dismutase activity.

\section{Statistical analysis}

Values obtained in triplicates were subjected to two way ANOVA and values expressed as Mean \pm standard deviation. Values at $\mathrm{P}<0.05$ were considered statistically significant.

\section{Results and Discussion}

Some researchers have shown that electromagnetic fields (EMFs) penetrate living organisms and alter the cell membrane potential. This alteration may affect free-radical processes within the cell and alter the activities of antioxidant enzymes, particularly CAT and SOD in different organs. Our research, therefore, investigated the variation effects of mobile phone frequencies and exposure duration on selected oxidative stress biomarkers in rats. 
Super oxide dismutase activities were assessed in the experimental samples. The activities of the enzyme in all the treatment groups for 90 and 180 days showed significant $(\mathrm{p}<0.05)$ increase when compared to the control groups. The highest activities of the enzyme were observed in the groups exposed to $2.4 \mathrm{GHz} /$ day radiation for 90 and 180 days, as shown in Figure 1a. Progressive changes in the enzyme activities were observed. The changes were relatively slowing within the exposure range of 5 to $15 \mathrm{~h} /$ day, and sharply hiked at the exposure to $2.4 \mathrm{GHz} /$ day, as shown in Figure 1b.

The activities of catalase in the experimental samples were assayed. The activities of the enzyme in all the treatment groups were significantly $(\mathrm{p}<0.05)$ higher than the control groups as shown in Figure 2a. Changes in the catalase activities were also examined, Figure $2 \mathrm{~b}$, and from the plot, it can be deduced that the changes are proportional to the exposure duration. Increased catalase activity among the treatment groups, therefore; is a pointer to the existence of free radicals in the experimental samples.

In this study, the results demonstrated an increase in enzymatic antioxidant (superoxide dismutase and catalase) activities. Antioxidant is a substance that delays or inhibits oxidative damage to target molecules. ROS are continuously neutralized by antioxidants present in body tissues. Whenever the production of ROS exceeds the scavenging capacity of antioxidants, oxidative stress (OS) sets in. It has been established that electromagnetic fields increase the free
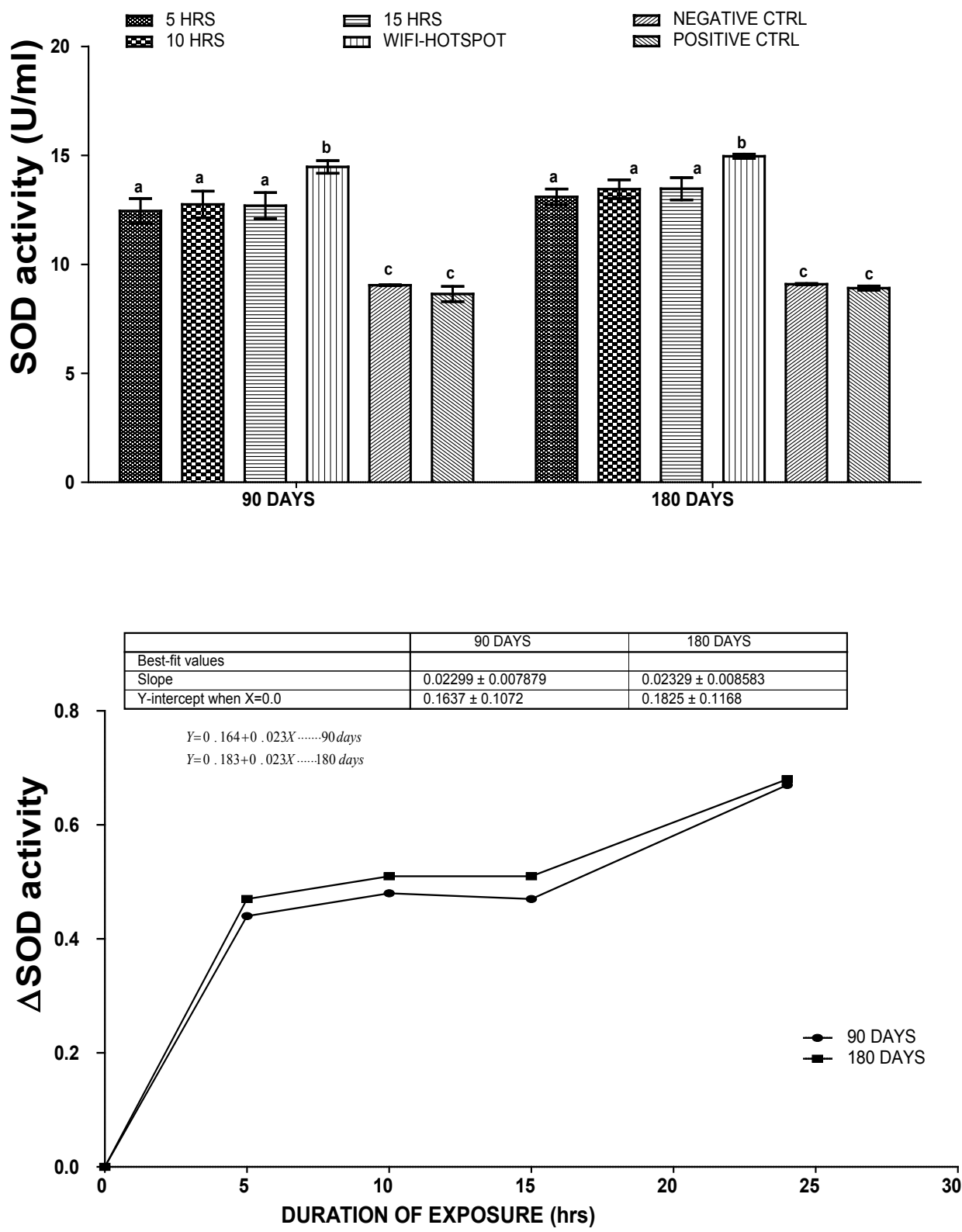

Figure 1: (a) SOD activities (IU/ml) of the samples. Bars are mean \pm standard deviation. Bars bearing different letters per treatment duration are statistically significant $(p<0.05)$ when SOD activities $(I U / \mathrm{ml})$ values of days 90 and 180 were compared for each treatment; (b) Changes in SOD activities (IU/ml) of the samples. The progressive changes (b) in the activities of the enzyme indicates the existence of the free radicals. When the groups exposed to wifi radiation were compared to the control groups in each exposure periods, statistical $(p<0.05)$ difference existed as shown in $(a)$. 

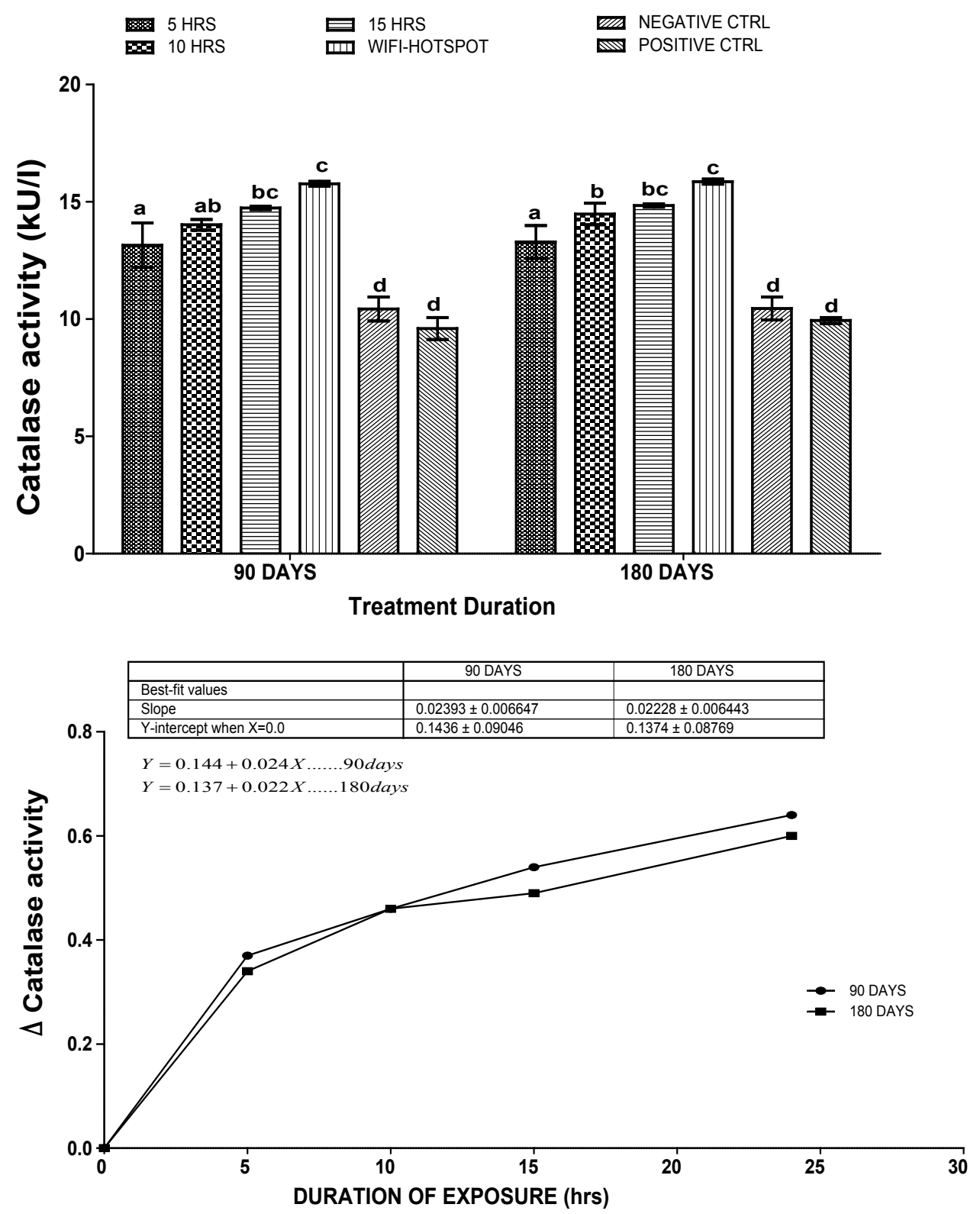

Figure 2: (a) Catalase activities (IU/ml) of the samples. Bars are mean \pm standard deviation. Bars bearing different letters per treatment duration are statistically significant $(p<0.05)$ when CAT activities $(\mathrm{IU} / \mathrm{ml})$ values of days 90 and 180 were compared for each treatment; (b) Changes in CAT activities (IU/ $\mathrm{ml}$ ) of the samples. The progressive changes (b) in the activities of the enzyme indicates the existence of the free radicals. When the groups exposed to wifi radiation were compared to the control groups in each exposure periods, statistical $(p<0.05)$ difference existed $(a)$.

radical activity in cells. And this has been proven by our in vivo animal studies which showed that oxidative stress develops in response to cell phone radiation. EMR may disturb ROS metabolism by increasing the production of ROS or by increasing the activity of antioxidant enzymes.

The results of our findings in SOD and catalase activities are in agreement with the findings of Kesari et al. [15] who reported an increase in catalase and superoxide dismutase activities in albino rats exposed to EMR.

Figure 3a showed the concentrations of malondialdehyde (MDA) in the experimental samples. From the figure, the concentration of MDA in all the treatment groups were significantly $(\mathrm{p}<0.05)$ higher when compared to the control groups, with the subgroups exposed to $2.4 \mathrm{GHz} /$ day showing more increased MDA concentration. In Figure $3 \mathrm{~b}$, the changes in the MDA concentration was shown with insignificant $(\mathrm{p}<0.05)$ changes among the sub-groups exposed at the range of 5 to $15 \mathrm{~h} /$ day. The concentration of the MDA however skyrocketed at the exposure to $2.4 \mathrm{GHz} /$ day for 90 and 180 days.

Our study demonstrated a significant increase in the lipid peroxidation product, malondialdehyde, as was observed in the treatment group. This result corroborates with the finding of Kesari et al. [15] who reported similar trend in malondialdehyde concentration following exposure to radiation. EMR exposure may cause generation 


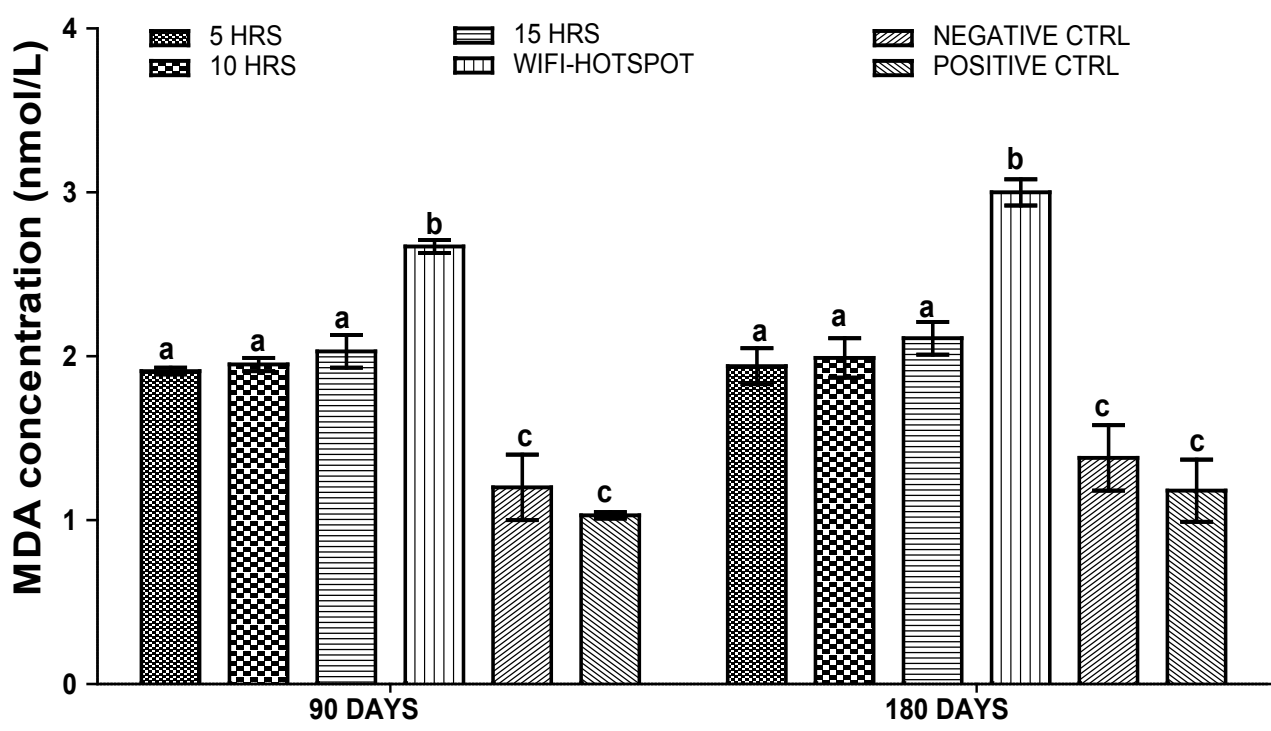

Treatment Duration

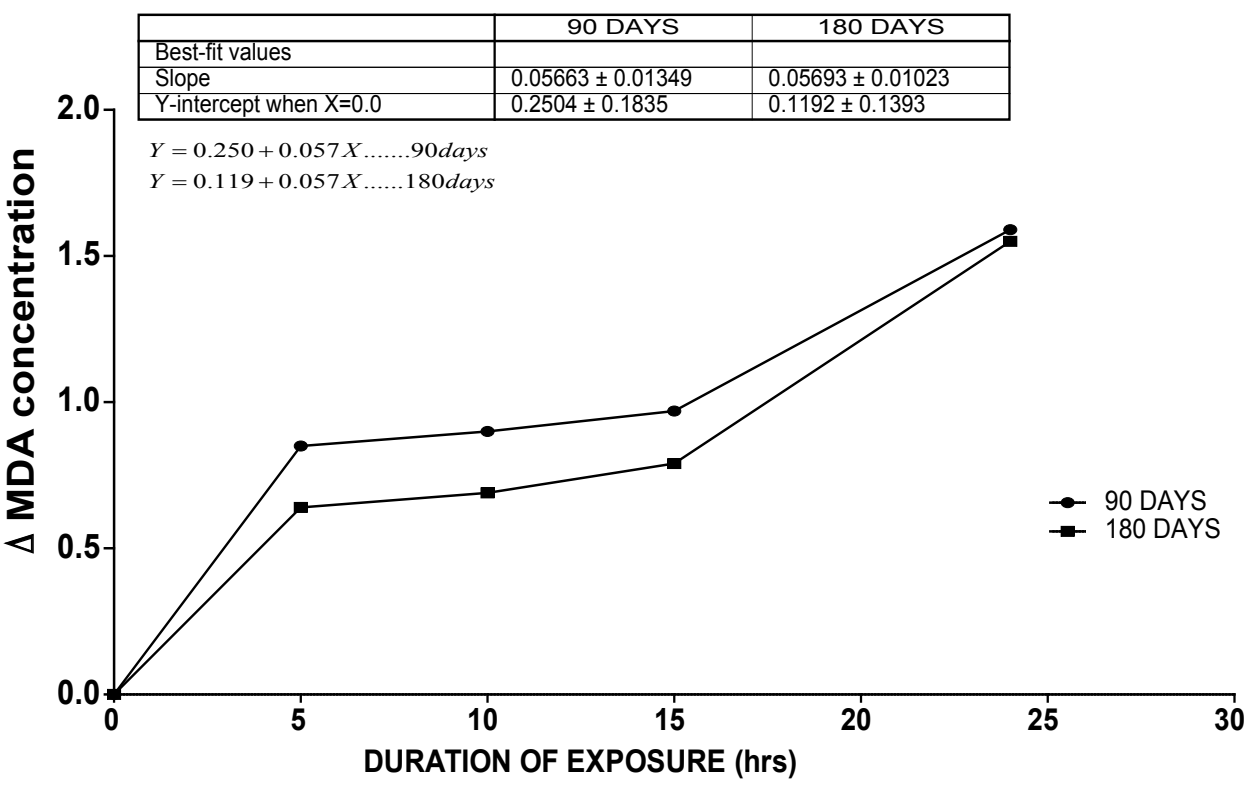

Figure 3: (a) MDA concentration (nmol/L) of the samples. Bars are mean \pm standard deviation. Bars bearing different letters per treatment duration are statistically significant $(p<0.05)$ when MDA concentration $(\mathrm{nmol} / \mathrm{L})$ values of days 90 and 180 were compared for each treatment; (b) Changes in MDA concentration $(\mathrm{nmol} / \mathrm{L})$ of the samples. The progressive changes $(\mathrm{b})$ in the concentration of the MDA showed progressive lipid peroxidation of the sperm cell. When the groups exposed to wifi radiation were compared to the control groups in each exposure periods, statistical ( $p<0.05)$ difference existed $(a)$.

of reactive oxygen species within a living cell, the ROS generated in turn bind to biomolecules ultimately resulting to lipid peroxidation and hence the elevated level of MDA demonstrated in this present study. Bediz et al. [16] proposed that long-term exposure to low-frequency EMR increases lipid peroxidation in the brain and other body organs and our findings were in agreement with the proposal.

\section{Conclusion}

The study was on the variation effects of mobile phone frequencies and exposure durations on selected oxidative stress biomarkers. Increase in the activities of the studied enzymes and the concentration of the MDA was observed. The increase in enzyme activities was proportional to the exposure duration and more so, to the high frequency. The animals exposed to $2.4 \mathrm{GHz}$ field and the exposure duration of 180 days recorded the highest enzyme activities and MDA concentrations. This confirmed frequency and exposure duration as keys to the negative effects of radiations from mobile phones. We therefore conclude that high mobile phone frequency, (as seen in wifi) and long exposure duration, can induce oxidative stress in living system.

\section{References}

1. Bakr AD (2004) Study of Microwave Effects on Biophysical and Histological Properties of Rat Brain, Ph.D. Thesis, Physics Department, Faculty of Science, Benha Branch, Zagazig University, p: 21.

2. Ozguner M, Koyu A, Cesur G, Ural M, Ozguner F, et al. (2005) Biological 
Citation: Iheme Cl, Omeh YN, Nwuke CP (2018) Variation Effects of Mobile Phone Frequencies and Exposure Durations on Selected Oxidative Stress Biomarkers of Male Wistar Albino Rats. Biochem Anal Biochem 7: 360. doi: 10.4172/2161-1009.1000360

and morphological effects on the reproductive organ of rats after exposure to electromagnetic field. Saudi Med J 26: 405-410.

3. Oktem F, Ozguner F, Mollaoglu H, Koyu A, Uz E (2005) Oxidative damage in the kidney induced by $900-\mathrm{MHz}-e m i t t e d$ mobile phone: Protection by Melatonin Arch Med Res 4: 350-535.

4. Barnes FS (1996) The effect of ELF on chemical reaction rate in biological systems. Biological effects of magnetic and electromagnetic fields, Plenum Press, New York, pp: 37-44.

5. Moore HA, Raymond R, Fox M, Galsky AG (1979) Low-intensity microwave radiation and the virulence of Agrobacterium tumefaciens strain B6. Appl Environ Microbiol 37: 127-130.

6. Gandhi OP (1987) Biological Effects of Electromagnetic Radiation. IEEE Engineering in Medicine and Biology 6: 14-58.

7. Valko M, Leibfritz D, Moncol J, Cronin MTD, Mazur M, et al. (2007) Free radicals and antioxidants in normal physiological functions and human disease. Int J Biochem Cell Biol 39: 44-84.

8. EI-HAHMA (2012) Lipid Peroxidation End-Products as a Key of Oxidative Stress: Effect of Antioxidant on Their Production and Transfer of Free Radicals. In Lipid Peroxidation. InTech pp: 63-87.
9. Young IS, Woodside JV (2001) Antioxidants in health and disease. J Clin Pathol 54: 176-186.

10. Nair V, O'Neil CL, Wang PG (2008) Malondialdehyde Encyclopedia of Reagents for organic synthesis. John Wiley and Sons, New York.

11. Moore K, Roberts LJ (1998) Measurement of lipid peroxidation. Free radic Res 28: $659-671$.

12. Wallin B, Rosengren B, Shertzer HG, Camejo G (1993) Lipoprotein oxidation and measurement of TBARS formation in a single miroliter plate: Its use for evaluation of antioxidants. J Anal Biochem 208: 10-15.

13. Abei HE (1983) Catalase. In: Methods of Enzymatic Analysis. (3rdedn), Bergmeyer, Int: Weinhem, Deefield beach.

14. Xin Z, Waterman DF, Henken RM, Harmon RJ (1991) Effect of copper status on neutrophil function; superoxide dismutase and copper distribution in stress. J Diary Sci 74: 3078-3085.

15. Kesari KK, Kumar S, Behari J (2011) Effects of radiofrequency electromagnetic waves exposure from cellular phone on reproductive pattern in male Wistar rats. Appl Biochem Biotechnol 164: 546-559.

16. Bediz CS, Baltacy AK, Mogulkoc R, Oztekin E (2006) Zinc supplementation ameliorates electromagnetic field-induced lipid peroxidation in the rat brain. Tohuko J Exp Med 208: 133-140. 